\title{
English Language Learning Strategies Reported By Advanced Language Learners
}

Juyeon Lee, Hankuk University of Foreign Studies, Seoul, Korea

Michael Heinz, Hankuk University of Foreign Studies, Seoul, Korea

\begin{abstract}
The purpose of the present study is to investigate effective English language learning strategies (LLSs) employed by successful language learners. The participants in this study were 20 student interpreters enrolled in the graduate school of interpretation and translation in Korea. Data on LLSs were collected through unstructured essay writing, a method employed to encourage participants to freely reflect on their language learning experiences and report what strategies and study methods helped them develop a high level of English proficiency. Qualitative data analysis produced several findings related to the use of learning strategies. Specifically, metacognitive strategies, such as disciplined approach to language learning and monitoring of progress, and cognitive strategies, such as readingaloud and text analysis, were frequently mentioned as effective strategies. In addition, a number of participants emphasized the importance of conscious attention to language input during language learning activities. Testimonies of advanced English language learners in an English as a Foreign Language (EFL) context suggest that learner autonomy manifested in self-regulated learning activities may be crucial for successful foreign language learning. These and other findings are discussed with respect to their pedagogical implications for strategy-based instruction in English education.
\end{abstract}

Keywords: Language Learning Strategies (LLS); Learner Autonomy; Metacognitive Strategies

\section{INTRODUCTION}

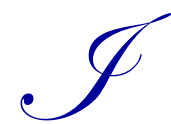
n today's world, the global spread of English is "unprecedented and unparalleled" (Seidlhofer, 2011). English has become the preferred language of choice for international communication in a variety of domains, thus gaining the status as a lingua franca. As such, English language skills have been recognized in Korea as essential skills to acquire in order to be successful in a globalized society. English is a core element of the secondary school curriculum, and college students study English to find good jobs after graduation. From a young age, Korean children spend many hours every week studying English and often go to private English academies and institutes to improve their English language skills (For a critical review of Koreans' zeal for English education, see Kang, 2014). Similar to Japan (Takeuchi, 2003), books on how to study English are abundant in bookstores. In short, there is a keen interest in what it takes to be a successful language learner.

Early research on key factors to successful language learning began with empirical studies on the behaviors of good language learners (GLLs), such as Rubin (1975) and Stevick (1989). In addition, research on learner characteristics attempted to identify particular traits that seem to be shared by successful language learners, ranging from intelligence and aptitude to personality and learner beliefs (Lightbown \& Spada, 1999). There may be a varying degree of correlations between language learning outcomes and these traits, but it has been pointed out that individual characteristics do not predict the success of language learning with accuracy. Another relevant strand of research was aimed at identifying specific learning strategies employed by good language learners (O'Malley \& Chamot, 1990; Oxford, 1990, Wenden \& Rubin, 1987, among others). In more recent years, studies on learning strategy instruction and learner autonomy have demonstrated that language learning strategies (LLSs) can be instructed to language learners and that learner autonomy together with motivations for language learning can lead to successful language learning outcomes (e.g., Ho \& Crookall, 1995; Keene \& Zimmermann, 1997; Kim 2013).

In this context, it is worth noting that learning English as a foreign language (EFL) is a different context from learning English as a second language (ESL). While the latter is an input-rich learning context, the first is a context that offers 
limited exposure to authentic language input. As Takeuchi (2003) points out, therefore, different language learning strategies may be needed or preferred in an EFL context. This study was designed to investigate language learning strategies employed by successful English language learners. To this end, 20 graduate students enrolled in the Department of Korean and English at a graduate school of interpretation and translation in Korea were recruited as participants. Reports of these participants on their successful English language learning experiences are qualitatively analyzed to draw implications for English language learners in Korean and other EFL contexts.

\section{THEORETICAL BACKGROUND}

\section{Research on Good Language Learners}

Everyone learns his or her first language and the process of learning one's first language seems almost effortless. Yet, when it comes to learning additional language, whether it is a foreign language or a second language, some people seem to be more successful than others. This observation motivated early studies on characteristics of successful language learners, which examined good language learners (GLLs) from a multitude of angles. For instance, a number of personality characteristics have been proposed to influence second language learning (see Lightbown \& Spada, 1999, for a review). Genesee (1976) discussed the role of intelligence in second language learning. Other learner factors discussed as influential on language learning include aptitude, age and learner beliefs.

In addition to research on traits of individual language learners, another strand of research focused on what successful language learners do. Rubin (1975) states, "if we knew more about what the "successful learners" did, we might be able to teach these strategies to poorer learners to enhance their success record" (p. 42). Based on the belief that the strategies of GLLs would help less successful language learners, Rubin presented several key characteristics of GLLs. Specifically, the good language learner is "a willing and accurate guesser" (p. 45) and "prepared to attend to form" (p. 47). GLLs also practice and monitor their own and the speech of others. These studies on good language learners (GLLs), such as Rubin (1975), and Stevick (1989), show that there are certain behaviors for learning commonly observed among successful language learners. These findings suggest that research on GLLs' strategies might teach us how to develop English proficiency more effectively. Since then, a number of empirical studies have been conducted to document the strategies used by GLLs and the factors affecting their use.

\section{Research on Language Learning Strategies}

In the field of learning strategy research, language learning strategies can be defined as "strategies that contribute to the development of the language system which the learner constructs and affect learning directly" (Rubin, 1987, p. 23). O'Malley and Chamot (1990) described learning strategies as "the special thoughts or behaviors that individuals use to help them comprehend, learn, or retain new information" (p. 1). It has been documented that language learning strategies not only promote language learning but also contribute to increased learner-directed learning. Therefore, research on language learning strategies can produce insights that can better guide language learners.

Several early studies on language learning strategies were carried out to identify what kinds of learning strategies are effective for language learning. For instance, O'Malley and his colleagues (O'Malley et al, 1985; O'Malley \& Chamot, 1990, among others) examined the use of strategies by learners of English as a Second Language (ESL) and categorized the strategies into three groups: metacognitive strategies, cognitive strategies, and socio-affective strategies. Metacognitive strategies are used to plan for learning, reflecting on the learning process, monitoring one's production or comprehension, and evaluating learning after an activity is completed (Purpura, 1997). Cognitive strategies are employed while learners carry out specific learning tasks. Socio-affective strategies are concerned with social mediating activity in interactions with others. As such, some of the socio-affective strategies can also be referred to as communication strategies.

In an attempt to facilitate research on LLSs, Oxford (1990) designed the Strategy Inventory for Language Learning (SILL), which is a self-report questionnaire that can be used to investigate the use of strategies by language learners in a variety of settings. In the SILL, language learning strategies are grouped into six categories: memory strategies for storing and retrieving information, cognitive strategies for language comprehension and production, compensation strategies for overcoming constraints in language learning, metacognitive strategies for planning and monitoring 
learning, affective strategies for controlling emotions and motivation, and social strategies for cooperation with others in language learning. This instrument has been used extensively in research on LLSs (e.g., Hong-Nam \& Leavell, 2006; Nisbet et al, 2005).

Numerous empirical studies were carried out to document the use of LLSs in their language learning. For instance, O'Malley et al (1985) interviewed ESL students and teachers to identify strategies employed in classrooms and other settings and found that they used a variety of learning strategies to carry out language learning activities. Griffiths and Parr (2001) used SILL to survey preferences of LLSs among adult ESL learners in New Zealand and reported that social strategies and metacognitive strategies were used most frequently. In another study on adult ESL learners by Hong-Nam and Leavell (2006), students in the intermediate level were found to use learning strategies more frequently than those in the beginner and advanced levels and that these students preferred to use metacognitive strategies.

Individual language learners may employ learning strategies differently, and strategy use has been known to be influenced by a number of factors. They include "motivation, the language learning environment, learning style or personality type, gender, culture or national origin, career orientation, age, and the nature of the language task" (Oxford, 2001, pp. 170-171). Therefore, researchers may need to take into account these factors in analyzing and accounting for the use of LLSs by different learner groups. One important factor that has informed the present study is the language learning environment. More specifically, the distinction between an EFL environment and an ESL environment may influence strategy preferences by learners.

In this regard, Takeuchi's (2003) study bears much implication for the present study. Takeuchi argues that "the strategies frequently used by GLLs in an Asian FL (foreign language) context differ drastically from those in the North American SL (second language) context)" (p. 385). The qualitative data analyses on good foreign language learners showed that metacognitive strategies such as "maximizing opportunities to use the language," and "learning regularly" (p. 386) were preferred strategies to maximize language input and practice. The author explains that such metacognitive strategies are favored due to the foreign language learning context. Likewise, the present study took into consideration the fact that most participants have studied English in an EFL context, which may have motivated them to choose certain strategies over others.

\section{Research on Learner Autonomy}

Another part of the literature that has informed the present study is research on learner autonomy. Autonomous and self-directed learning is crucial especially in the EFL context. As Kim (2013) rightfully argues, learner autonomy and self-directed learning are essential in an EFL environment where there are not many opportunities to use English and be exposed to authentic language use. Cotterall (1995) defines autonomy as "the extent to which learners demonstrate the ability to use a set of tactics for taking control of their learning" (p. 195). In this regard, Little (1995) posited that "the basis of learner autonomy is that the learner accepts responsibility for his or her learning" (p. 175).

In the social cognitive theory, autonomous learning has been discussed in terms of self-regulated learning. The selfregulated process includes the performance phase, self-reflection phase and forethought phase (Zimmerman, 2011). In the performance phase, a crucial element is self-observation, which involves metacognitive monitoring of one's performance, the relevant conditions related to such performance, and their effects. In the EFL context, learners with a strong sense of autonomy may engage in self-regulated learning activities, which includes actively pursuing opportunities to use the language, monitoring their own learning activities, and taking control of their learning.

Research has been carried out on this important topic. For instance, Ho and Crookall (1995) used simulation to transform the ordinary classroom in China into a learning environment that fosters learner autonomy. They reported that autonomy can be learned through the concrete actions of taking responsibility for their own learning process. Autonomous learners are able to engage in self-directed learning activities. In another study, Kim (2012) examined the relationship between motivational factors and self-directed learning ability and found that the high achieving group tended to be more intrinsically oriented and more self-directed in their approach to English language learning.

As discussed in this section, previous research suggests that good language learners are in control of their learning and reflective of their learning process and outcomes. In this process, they employ various language learning strategies to 
achieve successful learning. In this context, the present study analyzed data from advanced L2 speakers of English to discuss characteristics of autonomous learners.

\section{THE STUDY}

\section{Participants}

To investigate what language learning strategies were favored by advanced L2 speakers of English, the present study recruited 20 students of the Department of Korean and English at the Graduate School of Interpretation and Translation in H University in Korea. At the time of the data collection, they were in the first semester of the two-year graduate program. Among the 20 participants, 17 were female and 3 were male, which reflects a female-dominant demographic characteristic of this graduate school. As Korea's oldest graduate school specialized in interpretation and translation education, the program teaches students interpretation and translation techniques to train them as professional interpreters and translators. To get admitted to this competitive program, applicants are required to have a very strong command of the foreign language of their choice. Since the participants were admitted to the program, they can be considered to be advanced speakers of English. Indeed, a study by Heinz (2013) on a group of students enrolled in this graduate program attested the advanced level of English language proficiency of this population.

One criterion was critical in the process of selecting participants for the present study, which was the onset of stayingabroad. Among the students in the graduate program, a number of them have lived abroad when they were younger. In order to elicit data on English language learning strategies consciously utilized by the learners and to draw implications relevant to the EFL context, students who lived overseas before adolescence were excluded from the study. Some of the participants included in the study indeed lived abroad for a period ranging from as short as 6 months to as long as 4 years, but they all lived in other countries after the age of 15 .

\section{Data Collection and Analysis}

The purpose of the present study was to explore language learning strategies that the advanced English speakers have used. In order to avoid imposing pre-determined categories or types of strategies and allow participants to freely share their experiences, the unstructured essay writing was used as a data collection method. The participants were asked to write an essay on English language learning experiences and discuss what strategies were effective. Specifically, the question read as follows: "Please reflect on your second language learning experiences. Describe what you have done to improve your English language skills. Why do you think some of the strategies or approaches were effective and why some of them were not very successful?" The participants were given one week to complete the essays in English. There was a minimum length requirement of 300 words.

Since the main data consisted of unstructured written essays, a qualitative approach to data analysis was adopted. Analyses of qualitative data often begin with the identification of key themes and patterns (Coffey \& Atkinson, 1996). As such, the researcher carefully read the essays several times to get a sense of the recurring themes in the students' responses. This process was used to condense the data into analyzable units by creating categories from the data. While the categorization of language learning strategies into metacognitive, cognitive, and communicative strategies informed and guided the data analysis process, effective and ineffective language learning strategies were not categorized $a$ priori but emerged from the data through careful and mindful reading of the essays.

First, the texts were color-coded in terms of metacognitive, cognitive, and communicative strategies. In addition, there were many instances in the essays where the participants discussed why certain strategies were useful and why other strategies did not promote language learning. These factors and reasons were identified and categorized as they would offer insights into what it takes to achieve successful language learning.

The data analysis resulted in a number of qualitative findings, which give us a better understanding of what may have contributed to developing a high level of English language competence in the EFL context and how teachers may encourage English learners to become autonomous learners with the ability to utilize various effective language learning strategies. 


\section{RESULTS}

The unstructured essays written by the participants included a variety of effective and ineffective strategies and study methods. Since pre-determined categories of strategies were not provided to the participants, their reports on strategies take on various forms. In many instances, statements about certain strategies can be categorized as both metacognitive and cognitive strategies. In other instances, some strategies refer to broader approaches to language learning while other strategies refer to specific language learning activities and tasks. Given the qualitative and unstructured nature of the collected data, the findings take the form of qualitative findings with reference to actual statements written by the participants. First, strategies reported by the participants as contributing to developing English proficiency are discussed, followed by the discussion of strategies and study methods rated by the participants as ineffective and unhelpful. This section concludes with implications of the present study's major findings.

\section{Effective Strategies}

In the present study, the most frequently cited strategies were metacognitive strategies, which are strategies learners use to plan and monitor their own language learning. Specifically, 12 participants included in their essays strategies and approaches that can be broadly categorized as metacognitive strategies. Some examples are as follows:

1. (P5) "had a routine of learning a short English story by heart each day"

2. (P9) "practicing 30 minutes a day every day is better than studying 10 hours once in a while"

3. (P11) "I made sure to borrow 30 books a day and read them aloud"

Discussing these disciplined approaches to language learning, several participants emphasized the need for repetition. For instance, P4 described herself as "a strong believer of repetition" in language learning and persistency in English language study was crucial for her success. Other participants also argued that continued repetition and conscious efforts to study good expressions and texts was very effective. These remarks indicate strong learner autonomy as the participants exhibited the ability to take control of their learning (Little, 1995). Furthermore, this finding is in line with Takeuchi's (2003) findings that learning regularly is a key for the success of language learning.

Secondly, ten participants reported that they have made conscious efforts to memorize expressions and incorporate them into their English competence. These efforts include "listening to the same dialogue twice a day until I was able to hear everything" (P4), "found good expressions and collocations and read and wrote them as many times as possible" (P17), "memorizing expressions, sentences and even a whole speech" (P9), and "made deliberate efforts to memorize paragraphs and then speak or write them" (P12). Their determination to practice English and efforts to integrate newly learned expressions and words into their English represents strong motivation for English learning as well as learner autonomy. Also, these statements remind us of what Rubin (1975) described as traits of good language learners as being prepared to attend to form and practice language.

Thirdly, seven participants emphasized the need for increased exposure to English. As most of the participants have studied English in an EFL context, opportunities to use English and be exposed to authentic language input may be limited. Despite these constraints, the participants were motivated to increase their exposure to English in a variety of ways. For instance, several participants (P1, P5, P19, and P20) actively utilized various written texts as a source of language input. P19 wrote, "I paid attention to anything written in English such as manuals and product labels." Also, P20 argued that "reading was the only plausible option. I spent more than 90 percent of my time in reading. I read any text that I could get my hands on; newspaper articles, manuals, email newsletters, notices at airports and even game manuals." A couple of participants resorted to listening to the radio and watching American TV shows and news to access authentic language input. These strategies can be understood in the context of an EFL environment where opportunities to use language are limited. In spite of these limitations, successful language learners actively pursued sources of language input and increased exposure to input.

It was interesting to note that six participants noted the value of reading aloud. They explained that reading aloud can help learners develop various aspects of language competence. For instance, P1 wrote, "reading simple sentences out loud helped me get used to speaking in English. Saying simple words and sentence structures out loud made them more unforgettable." Also, according to P10, "reading aloud helps to learn when to pause and how to play out stories." It was 
also argued that "reading a lot helps with increased input and collocations and even helps with writing." This finding is supported by Takeuchi (2003) that "reading aloud many times and reading a lot are the two strategies preferred most by GLLs in the Japanese FL context" (p. 386). In both studies, learners were found to use reading aloud as a means to develop phonological and semantic awareness and internalize the linguistic system.

In addition to the strategies described above, several participants mentioned tactics and strategies concerned with specific language skills. To improve listening, P4 listened to the same dialogues and recordings repeatedly until she was able to hear every word. With respect to speaking skills, P2 observed how a native speaker moves his mouth and body and tried to imitate them. P8 mimicked her favorite drama characters to improve pronunciation and overall speaking ability. P15 tried to speak English at least an hour a day, believing that speaking out loud was the best way to enhance English skills. In addition, to develop English writing skills, P13 copied down good texts, P14 wrote journals in English, and P1 practiced creative writing to "let yourself loose from the pressure to use perfect grammar and use language in a creative way." As Oxford (2001) points out, many factors influence strategy use and the participants in the present study may have applied different strategies depending on their learning environment, culture, personality type or other relevant factors. What is important is for these learners to be keenly aware of their learning process and make conscious decisions on strategies as autonomous learners.

\section{Ineffective Strategies}

This section presents strategies evaluated by the participants as unhelpful for their language learning. Before the discussion of ineffective strategies, it is important to note that some participants included in their essays ineffective learning strategies while others focused only on effective strategies. This section reports mainly on those who mentioned ineffective study methods. First of all, eight participants argued that rote memorization of vocabulary was not helpful. For instance, P4 argued that words did not stay with her when she tried to memorize hundreds of words a day. Similarly, P2 and P9 wrote that memorizing words without understanding their meaning and usage was not effective. Rote memorization is part of a more traditional approach to foreign language teaching rooted in behaviorism (Lightbown \& Spada, 1999). Decades of studies in second language acquisition (SLA) have produced a rich body of research that demonstrates the need for attention to meaning and the use of language in a communicative and meaningful context. As one of the six categories of the SILL strategy grouping, certain memory strategies can help students remember language elements, but they need to be tied with meaning. Otherwise, rote memorization of vocabulary may not lead to the successful acquisition of new words.

Secondly, eight participants underscored the importance of conscious attention to language when receiving language input. In other words, receiving language input in a passive manner is not sufficient. Conscious attention and active engagement is crucial. Some examples are as follows:

1. (P6) "My attempt to improve my 'listening abilities' by playing cassette tape lessons didn't help me significantly because it was not preceded by a solid foundation in grammar and vocabulary."

2. (P13) "What I think now was ineffective was just reading some books but not studying them. Reading a lot clearly helps us in some ways. However, I read books but did not try to know exactly what they meant and how they worked in other sentences and contexts, believing that I understood what the stories they were about. This made me a passive learner, with nothing left in my memory."

3. (P14) "I tried to expose myself to English 24 hours day, so I turned on the English app even when I was not paying attention. Frankly speaking, I do not think that helped me a lot. I realized that even though you are exposed to English all the time, it does not seem to be effective if you are unconscious and not concentrating. You hear the words, but the words do not make any sense to you."

These remarks suggest the limitations of passive learning. That is, passive exposure to language input does not effectively lead to the development of linguistic and communicative competence. As research on input suggests (Bialystok, 1978; Ellis, 1997), conscious attention to input is needed for the input to be taken up by the learner in a meaningful context and later incorporated into the learner's explicit and implicit knowledge. As such, strategies such as leaving the English TV or radio on all the time without the learner's conscious attention to language is not likely to be effective. 
In addition, several participants wrote that too much emphasis on grammar was not very effective. While other participants such as P6 acknowledged the value of studying grammar to understand formal and structural aspects of the language, P2 viewed that grammar-centered instruction did not help her become fluent in speaking the language. One can assume that the participant referred to a more traditional English instruction method that centered on the grammar translation method. While the communicative approach to teaching English has been increasingly incorporated in the English curriculum in Korea, grammar instruction is still a major element of English education. Efforts can be made to turn grammar instruction into more communicative learning activities.

This section reports on strategies deemed ineffective by the participants in the present study. However, strategy use and its effectiveness can be mediated by a number of factors, and certain strategies considered ineffective for some learners may turn out to be helpful for other learners. Nisbet et al (2005) found that SILL strategies accounted for only $4 \%$ of the variation in TOEFL scores among Chinese university students and suggested the possible interplay of learner autonomy. These findings are indicative of the possibility that learners' application of strategies was inappropriate or not well managed. Nevertheless, several strategies judged ineffective by many successful language learners are something that both learners and teachers need to be mindful of.

\section{DISCUSSION}

The findings in the present study produced several insights on what successful language learners have done to achieve a high level of proficiency in English. First of all, the participants exhibited the characteristics of autonomous and selfregulated learners who take responsibility for their own learning and monitor their learning progress. Strategies related to this aspect are metacognitive strategies. In this regard, O'Malley and Chamot (1990) state that metacognitive strategies have been considered to be vital for successful learning in the relevant literature. In both Nisbet et al (2005) and Takeuchi (2003), the most frequently used strategies by language learners were metacognitive strategies.

Secondly, the participants seem to agree that conscious attention to formal and structural aspects of language are crucial for successful language learning. As DeKeyser (2002) points out, conscious learning plays an important role in second/foreign language acquisition. While focus on communication and the development of communicative competence has gained much attention in the field of SLA for the past couple of decades, it is equally important to raise learners' awareness on formal aspects of language. In this regard, Long (1991) proposed a focus on form and argued that grammar instruction incorporated in a meaning-based learning activity may enhance learners' ability to notice aspects of English that might otherwise go unnoticed while engaged in communication. These types of strategies that focus on form may be particularly effective for more advanced learners who have already acquired fluency and now turn their attention to improving accuracy.

Another finding is that most of the strategies reported by the participants in this study are the ones they employed on their own outside of the classroom settings. Together with the other findings, it presents pedagogical implications. As LLSs have been recognized as contributing to language learning, classroom instruction can focus on teaching useful strategies to English learners. In particular, as attested to by the participants in this study, metacognitive strategies are frequently used as effective strategies. Hong-Nam and Leavell (2006) suggest that teachers can "facilitate learning by addressing both content and process" as "learners indicate a high preference for metacognitive strategies which helped them in directing, organizing, and planning for their language learning" (p. 411). That is, English teachers can use class time to help students learn effective metacognitive strategies to plan and organize their language learning so that they can continue on their learning outside of the classroom as well.

Furthermore, it is important to bear in mind that different language learning strategies may be most helpful to students at different levels of proficiency (Chamot, 2004; Hong-Nam \& Leavell, 2006). Lee et al. (2011) discussed what strategies are covered in Korean middle school English textbooks and proposed a strategy instruction model for each school grade with respect to reading strategies. As seen in the findings of the present paper, strategies can contribute to enhancing language learning outcome. Thus, this line of research on LLS instruction needs to be continued.

Finally, strategy instruction needs to also focus on showing students how to utilize different strategies, such as metacognitive, cognitive, social and other strategies, appropriately. Vann and Abraham (1990) reported on the strategies of unsuccessful language learners. In the qualitative study on two Saudi Arabian English learners, 
unsuccessful language learners emerged as active strategy users but they often applied strategies inappropriately. As such, teachers may devise classroom activities that require different strategies and encourage students to select and apply appropriate strategies in a given context.

\section{CONCLUSION}

The present study aimed at exploring effective English language learning strategies used by successful language learners. Qualitative analyses of data obtained from unstructured essay writing by 20 graduate students of interpretation and translation produced several key findings. The participants reported the frequent use of metacognitive strategies to manage their learning and increase exposure to English input. The participants also emphasized the need for conscious attention to formal aspects and expressions contained in language input and efforts to internalize them. They preferred reading aloud as a particular learning strategy to develop a feel for the language, improve fluency, and acquire useful expressions. While they reported the usefulness of exposure to English input through reading and other measures, they argued that passive exposure to English would not produce desired outcomes. The pedagogical implications of these findings were also discussed.

As the participants in this study are highly motivated learners, they may not represent a general population of learners. Thus, the findings of the study may not be generalizable to other kinds of learners. As Oxford (1990) points out, a host of other factors may motivate certain strategy use and influence their effectiveness. Nevertheless, the findings of this study provide a guide for English learners and teachers on what was proven effective by successful language learners.

With respect to future research, it would be helpful to use two or three types of data so that triangulation can help establish the validity of the research. The present study only collected essays written by the participants without much structure or categorization provided to the learners in advance. As Chamot (2004) suggests, focus group interviews, questionnaires, think-alouds and other data collection methods can be used in combination to obtain more comprehensive information about a specific group of learners with respect to strategy use.

In addition, an empirical study on the instruction of metacognitive strategies may contribute to the field. Metacognitive strategies may be combined with instructional activities to promote learner autonomy so that learners can be encouraged to become more in control of their language learning and be equipped with concrete tools and strategies to exercise autonomy in planning and monitoring their learning.

\section{ACKNOWLEDGEMENT}

This paper was supported by the 2016 Research Fund of Hankuk University of Foreign Studies.

\section{AUTHOR BIOGRAPHIES}

Juyeon Lee is an assistant professor at Hankuk University of Foreign Studies in the Graduate School of Interpretation and Translation. As a professional conference interpreter with more than 10 years of experience, her research interests include cognitive processes of interpreting, interpreter education and training as well as linguistic features exhibited in conference interpretation between Korean and English. In addition, as a holder of a doctorate degree in language education, she is interested in understanding successful language learners in Korea with a high level of English language proficiency. Juyeon Lee earned an Ed.D. in Language Education from Rutgers University in the U.S. International Building, 107 Imun-ro, Dongdaemun-gu, Seoul, Korea Email: juliajustin@gmail.com

Michael Heinz lectures fulltime at Hankuk University of Foreign Studies in the Graduate School of Interpretation and Translation. There, he teaches interpreters-in-training public speaking skills, stress management skills, critical thinking skills, and general academic skills to prepare them to work as both consecutive and simultaneous interpreters. Working with interpreters affords him the unique opportunity to research high level language learning tasks and profile the traits of successful language learners of two vastly differing languages like English and Korean. Michael Heinz earned both his B.S. in History and his Master of Arts in Education from Truman State University. Michael Heinz, Hankuk University of Foreign Studies, Seoul Korea. International Building, 107 Imun-ro, Dongdaemun-gu, Seoul, Korea. Email: michaelhistory@gmail.com 


\section{REFERENCES}

Bialystok, E. (1978). A theoretical model of second language learning. Language Learning, 28, 69-83.

Chamot, A. U. (2004). Issues in language learning strategy research and teaching. Electronic Journal of Foreign Language Teaching, 1(1), 14-26.

Coffey, A., \& Atkinson, P. (1996). Making sense of qualitative data. Thousand Oaks: Sage Publications.

Cotterall, S. (1995). Readiness for autonomy: Investigating learner beliefs. System, 23(2), 195-205.

DeKeyser, R. M. (2000). The robustness of critical period effects in second language acquisition. Studies in Second Language Acquisition, 22, 499-533.

Ellis, R. (1997). SLA research and language teaching. Oxford: Oxford University Press.

Genesee, F. (1976). The role of intelligence in second language learning. Language Learning, 26(2), 267-280.

Griffiths, C. \& Parr, J. M. (2001). Language learning strategies: Theory and perception. ELT Journal, 55(3), 247-254.

Heinz, M. (2013). A preliminary survey of the preferred learning methods for interpretation students. Journal of International Education Research, 9(4), 293-304.

Ho, J. \& Crookall, D. (1995). Breaking with Chinese cultural traditions: Learner autonomy in English language teaching. System, 23(2), 235-243.

Hong-Nam, K. \& Leavell, A. G. (2006). Language learning strategy use of ESL students in an intensive English learning context. System, 34, 399-415.

Kang, J. (2014). Koreans and English: Why do koreans worship English? Seoul: Inmulgwa Sasang.

Keene, E. O. \& Zimmermann, S. (1997) Mosaic of thought: Teaching comprehension in a reader's workshop. Portsmouth, NH: Heinemann.

Kim, Inyoung. (2012). SBI model development based upon the analysis of self-directed learning components: Focused on motivational and cognitive factors. Modern English Education, 13(2), 179-205.

Kim, Keumsun. (2013). A study on the self-directed classroom learning in the university setting. Modern English Education, 14(2), 189-212.

Lee, K. R., Kim, S., Kim, S., \& Lee, Y. (2011). English language learning strategy instruction in Korean English textbooks for middle school students' self-regulated learning. Modern English Education, 12(1), 177-201.

Lightbown, P. M., \& Spada, N. (1999). How languages are learned. Oxford: Oxford University Press.

Little, D. (1995). Learning as dialogue: The dependence of learner autonomy on teacher autonomy. System, 23(2), $175-181$.

Long, M. H. (1991). Focus on form: A design feature in language teaching methodology. In K. de Bot, R. Ginsberg, \& C. J. Kramsch (Eds.). Foreign language research in cross-cultural perspective (pp. 39-52). Amsterdam/Philadelphia, PA: John Benjamins.

Nisbet, D. L., Tindall, E. R., \& Arroyo, A. A. (2005). Language learning strategies and English proficiency of Chinese university students. Foreign Language Annals, 38(1), 100-107.

O’Malley, J. M., Chamot, A. U., Stewner-Manzanares, G., Russo, R. P., \& Kupper, L. (1985). Learning strategy applications with students of English as a second language. TESOL Quarterly, 19(3), 557-577.

O’Malley, J. M., \& Chamot, A. U. (1990). Learning strategies in second language acquisition. New York: Cambridge University Press.

Oxford, R. (1990). Language learning strategies: What every teacher should know. New York: Newbury House.

Oxford, R. (2001). Language learning strategies. In R. Carter \& D. Nunan (Eds.). Teaching English to speakers of other languages (pp. 166-172). Cambridge: Cambridge University Press.

Purpura, J. E. (1997). An analysis of the relationships between test takers' cognitive and metacognitive strategy use and second language test performance. Language Learning, 47, 289-325.

Rubin, J. (1975). What the "good language learner" can teach us. TESOL Quarterly, 9(1), 41-51.

Rubin, J. (1987). Learner strategies: Theoretical assumptions, research history and typology. In A. Weden \& J. Rubin (Eds.). Learner strategies in language learning (pp. 15-30). New York: Prentice Hall International.

Seidlhofer, B. (2011). Understanding English as a lingua franca. Oxford: Oxford University Press.

Stevick, E. (1989). Success with foreign languages: Seven who achieved it and what worked for them. New York: Prentice Hall International.

Takeuchi, O. (2003). What can we learn from good foreign language learners? A qualitative study in the Japanese foreign language context. System, 31, 385-392.

Vann, R. J., \& Abraham, R. G. (1990). Strategies of unsuccessful language learners. TESOL Quarterly, 25(2), 177-193.

Wenden, A., \& Rubin, J. (Eds.) (1987). Learner strategies in language learning. Englewood Cliffs, NJ: Prentice Hall.

Zimmerman, B. J. (2011). Motivational sources and outcomes of self-regulated learning and performance. In Schunk, D. H. \& Zimmerman, B. J. (Eds.). Handbook of self-regulation of learning and performance (pp. 49-64). Routledge Taylor \& Francis Group: New York and London. 


\section{NOTES}

